\title{
A PERCUSSÃO CORPORAL ASSOCIADA AO USO DE UM APLICATIVO PARA TABLET: MOVENDO E APRENDENDO COM O RITMO
}

\author{
Body percussion associated with the use of a \\ tablet application: moving and learning with \\ the rhythm
}

\author{
Percusión corporal asociada al uso de una \\ aplicación para tablet: moverse y aprender \\ con el ritmo
}

\author{
Marcio Pizzi De Oliveira \\ Centro Federal Educação Tecnológica Celso Suckow da Fonseca Cefet-RJ/Campus Valença \\ marcio.oliveira@cefet-rj.br
}

Resumo: A prática da percussão corporal tem sido utilizada como ferramenta relevante para fins de performance e aprendizado no campo da música. A incorporação de aplicativos para smartphone e tablet pela educação musical amplia a oferta de meios que possibilitam o exercício de habilidades relacionadas ao uso do corpo. O objetivo do artigo é entender o que acontece quando se associa a percussão corporal com um aplicativo para tablet no aprendizado de leitura musical. O presente trabalho utiliza os dados de minha tese de doutorado onde trabalhei com diversas práticas relacionadas ao uso de smartphones e tablets no âmbito da educação musical. A metodologia do trabalho utilizou observação participante, entrevistas e questionários com 79 alunos de duas unidades de uma escola técnica do Rio de Janeiro. Os resultados demonstram que apesar de algumas dificuldades geradas pelas mudanças de padrões rítmicos e a variação do andamento a prática apresentou recursos relevantes para o aprendizado musical.

Palavras-chave: Educação musical. Percussão corporal. Tablet.

\begin{abstract}
The practice of body percussion has been used as a relevant tool for purposes of performance and learning in the field of music. The incorporation of smartphone and tablet applications for music education expands the offer of means that enable the exercise of skills related to the use of the body. The purpose of the article is to understand what happens when associating body percussion with a tablet application in learning to read music. The present work uses the data from my doctoral thesis where I worked with several practices related to the use of smartphones and tablets in the scope of music education. The work methodology used participant observation, interviews and questionnaires with 79 students from two units of a technical school in Rio de Janeiro. The results demonstrate that despite some difficulties generated by the changes in rhythmic patterns and the variation in tempo, the practice presented relevant resources for musical learning.
\end{abstract}

Keywords: Music education. Body percussion. Tablet.

Resumen: La práctica de la percusión corporal se ha utilizado como una herramienta relevante para fines de interpretación y aprendizaje en el campo de la música. La incorporación de aplicaciones para smartphones y tablets para la educación musical amplia la oferta de medios que permiten el ejercicio de habilidades relacionadas con el uso del cuerpo. El propósito del artículo es comprender qué sucede cuando se asocia la percusión corporal con una aplicación para tablet para aprender a leer música. Este trabajo utiliza datos de mi tesis doctoral donde trabajé con varias prácticas relacionadas con el uso de smartphones y tablets en el ámbito de la educación musical. La metodología de trabajo utilizó observación participante, entrevistas y cuestionarios con 79 estudiantes de dos unidades de una escuela técnica en Río de Janeiro. Los resultados demuestran que a pesar de algunas dificultades generadas por los cambios en los patrones rítmicos y la variación del tempo, la práctica presentó recursos relevantes para el aprendizaje musical.

Palabras clave: Educación musical. Percusión corporal. Tablet. 


\section{INTRODUÇÃO}

O desenvolvimento de práticas com sons corporais no Brasil foi registrado inicialmente pelos portugueses no século XVI. Esses registros descreviam rituais e cerimônias indígenas no norte do país (Amorim, 2016, p. 36). $\mathrm{Na}$ cultura muçulmana a realização de sons corporais representa uma ferramenta de expressão cultural apresentando características que lembram gestos militares devido à precisão e ao virtuosismo (Kartomi, 2007, p. 1). O corpo como ferramenta musical foi estudado e incorporado como treinamento para músicos primeiramente por Émile Jaques-Dalcroze (1865-1950), que viveu durante anos no norte da Argélia (Romero-Naranjo, 2013, p. 445). Os exercícios criados por Dalcroze trabalham as sensações corporais e a percepção sonora como instrumentos de aprendizado musical.

A percussão corporal é a arte de tocar o corpo para produzir uma variedade de sons para fins didáticos, terapêuticos, antropológicos e sociais (Romero-Naranjo, 2013). O método BAPNE ${ }^{1}$ desenvolvido por Javier Romero-Naranjo oportunizou efeitos positivos para o uso da percussão corporal com fins terapêuticos. Estudos acerca da dislexia (Crespo-Colomino; Romero-Naranjo, 2014) e da reabilitação de drogados (Romero-Naranjo; Crespo-Colomino; Liendo-Cárdenas; Pons-Terrés; Carretero-Martínez, 2014) demonstram os benefícios da prática nesse campo. O uso da percussão corporal como ferramenta de performance e criação musical tem sido notabilizado no Brasil pela trajetória do grupo Barbatuques com a realização de shows, DVDs e propostas didáticas (Amorim, 2016). A disponibilização de conteúdo em sites e canais do YouTube também apresentam uma larga produção de performances e metodologias didáticas acerca da percussão corporal (Pereira, 2018).

Alguns estudos enfocaram a educação escolar como contexto para a aplicação de técnicas de percussão corporal. O grupo Barbatuques originou material que motivou a criação de práticas para a educação infantil (Barba; Núcleo Educacional Barbatuques, 2013; Mesquita, 2016). Estudos acerca da educação primária desenvolveram estratégias educativas utilizando a improvisação (Cremades Andreu, 2009), o exercício da expressão (Nedel, 2010), canções com palmas (Brodsky; Sulkin, 2011) e o aprendizado da matemática (Azaryahu; Courey; Elkoshi; Adi-Japha, 2019). A educação secundária também foi alvo de estudos acerca das competências sociais entre iguais (Fabra-Brell; Romero-Naranjo, 2017a, 2017b).

Verifica-se que a percussão corporal apresenta um grande potencial acerca do aprendizado musical, reunindo recursos motores, da fala e da visão (Romero-Naranjo, 2014, p. 534). Os estudos revelam a capacidade de sensibilização e integração dos sentidos no âmbito de estruturar uma musicalidade articulada entre o individual e o coletivo. No entanto, é possivel identificar

\footnotetext{
1 O termo BAPNE é um acrônimo formado pelas palavras Biomecânica, Anatomia, Psicologia, Neurociência e Etnomusicologia. O método BAPNE se vale da associação entre princípios e valores africanos com teorias psicofisiológicas e psicobiológicas no desenvolvimento de práticas de percussão corporal. Sua aplicação se dá no âmbito terapêutico auxiliando o tratamento de doenças como o Alzheimer e a doença de Parkinson.
} 
que o potencial da percussão corporal não foi plenamente contemplado pelos estudos sobre educação escolar. Observa-se que os estudos sobre o emprego da percussão corporal abrangeram de forma geral a performance, a expressão e a improvisação. Ao enfocar a educação escolar, verifica-se que a percussão corporal pode auxiliar de forma específica o aprendizado de estruturas teóricas como tempo, compasso e notação musical.

Estudos acerca do uso de smartphones no âmbito do aprendizado de instrumentos reportam efeitos positivos para o aprendizado musical (Cuervo, 2019; Palazón Herrera, 2014). Outros estudos realizaram experiências acerca do aprendizado do ritmo através de aplicativos de smartphone ou tablet (Chou; Chu, 2017; Wang; Mok; Meng, 2016; Zhou; Percival; Wang; Wang; Zhao, 2010). De maneira geral, os estudos acerca de tecnologias portáteis têm revelado grande potencial para o aprendizado musical, oferecendo possibilidades como o uso de vídeos, a inclusão de símbolos gráficos e dinâmicos e a praticidade de manuseio. Portanto, considera-se positiva a associação entre o uso dessas tecnologias e o aprendizado da notação rítmica musical.

O presente trabalho apresenta dados acerca de minha tese de doutorado, que trata do uso de aplicativos para smartphone e tablet no âmbito da educação musical. Aqui serão relatados elementos acerca de práticas de percussão corporal através do aplicativo Medly, para tablet, viabilizando o aprendizado de leitura rítmica. O processo de aprendizado se baseia na articulação entre elementos tradicionais de leitura rítmica e os símbolos presentes no aplicativo. O estudo envolveu 79 alunos de duas unidades de uma escola técnica do Rio de Janeiro. O artigo principia com uma revisão bibliográfica. Posteriormente, é apresentada a metodologia do trabalho. Em seguida é apresentada a configuração da prática implementada e os resultados da pesquisa. Por fim, estrutura-se uma discussão e a conclusão do artigo.

\section{A PERCUSSÃO CORPORAL E A TECNOLOGIA NO APRENDIZADO DA LEITURA MUSICAL}

Os estudos acerca da percussão corporal apresentaram formas distintas de notação musical. Os estudos baseados no modelo de percussão do grupo Barbatuques utilizam a estrutura da tablatura musical (Barba; Núcleo Educacional Barbatuques, 2013, p. 45). Essa tablatura apresenta o funcionamento semelhante ao das tablaturas de instrumentos de cordas, porém, ao invés das linhas representarem cada corda do instrumento, cada linha remete a um som de percussão corporal (estalo, palma, peito, etc.). No método BAPNE a notação musical só é apresentada depois que são memorizados todos os sons (Munari; Cozzutti; Romero-Naranjo, 2016, p. 2). A notação desse método é em geral grafada em um pentagrama convencional. O estudo que utilizou canções com palmas através do método BAPNE aplicou como forma de leitura cartões grafados com sequências de bolas e travessões, sendo as bolas palmas e os travessões silêncios (Brodsky; Sulkin, 2011, p. 1121).

Observa-se que os estudos apresentam formas de notação musical diversas. Porém, existe uma leve tendência de articular formas de notação menos 
tradicionais ou alternativas com a notação tradicional (Barba; Núcleo Educacional Barbatuques, 2013; Brodsky; Sulkin, 2011). Além disso, verifica-se a utilização da voz como recurso auxiliar (Barba; Núcleo Educacional Barbatuques, 2013). A utilização desses elementos pode produzir efeitos relevantes no âmbito da educação básica, pois tanto desenvolve formas menos convencionais de notação como oferece caminhos para introduzir a notação tradicional. Os estudos sobre percussão corporal aqui arrolados apresentam preocupações específicas com a performance musical e a terapia corporal. $\mathrm{O}$ produto final das práticas é em geral o aprendizado de músicas e arranjos percussivos. Assim, não foram estruturadas estratégias explícitas de aprendizado envolvendo noções de tempo, compasso ou escrita musical.

Nos últimos anos tem crescido o interesse por práticas que utilizem smartphones e tablets em sala de aula. Esse interesse motivou a criação do termo m-learning, que denota o exercício do aprendizado através de smartphones e dispositivos wireless em situações de sala de aula ou não (Dorairaju; Jambulingam, 2017, p. 40). Essa prática educacional já se consolidou em diversas áreas promovendo novas formas de estruturação do aprendizado. Essa tendência motivou o desenvolvimento de revisões sistemáticas enfocando o ensino da matemática, o ensino da ciência (Bano; Zowghi; Kearney; Schuck; Aubusson, 2018) e a educação superior (Crompton; Burke, 2018). O uso do m-learning no âmbito musical pode ofertar um entorno de aprendizagem ativo, aumentar a motivação dos estudantes e gerar comunidades de aprendizado (Palazón Herrera, 2014, p. 120-121).

Os estudos acerca do emprego de smartphones e tablets na educação musical apresentam recursos promissores para o aprendizado. Os novos aplicativos absorveram inovações provenientes da quarta revolução industrial oportunizando a utilização de recursos touchscreen, permitindo novas formas de execução instrumental (Cuervo, 2019; Duarte; Marins, 2015). Os elementos de registro musical variam da notação musical tradicional até notações alternativas advindas do processo de gameficação ${ }^{2}$ (Cuervo, 2019, p. 140). Os elementos trazidos pelos artigos remetem a um debate acerca da configuração das estratégias de ensino assim como a renovação de habilidades do professor em meio a uma realidade transformada no âmbito dos recursos pedagógicos. Alguns questionamentos surgem no âmbito da presente pesquisa: como inserir as novas formas de notação musical no ensino escolar? Esses elementos podem ser articulados com formas tradicionais de ensino?

Dois estudos promoveram a utilização de tecnologias digitais como forma de apoio para o aprendizado do ritmo. O desenvolvimento do sistema MusicSpeak ofereceu a oportunidade de utilizar smartphones no aprendizado do inglês através do canto (Wang; Mok; Meng, 2016). O estudo abordou o uso da prosódia musical variando o uso de silabas tônicas a átonas. A utilização de um aplicativo para tablet motivou a criação de uma prática rítmica com

\footnotetext{
2 A gameficação vem do termo gamefication, que consiste na utilização de elementos de games nos princípios de desenvolvimento de estratégias educacionais em situações exteriores ao jogo.
} 
crianças e robôs (Chou; Chu, 2017). Através de um sistema do tipo Arduino, os tablets foram conectados aos robôs fazendo com que os mesmos respondessem aos comandos dos dispositivos. Assim, as crianças puderam registrar trechos rítmicos nas interfaces dos tablets e presenciar o que foi registrado pela execução dos robôs. A incorporação do sistema MusicSpeak oportunizou a melhora da pronúncia em função do aprendizado rítmico (Wang; Mok; Meng, 2016, p. 79). Na prática com tablets e robôs, os alunos apresentaram uma melhora no interesse e na eficiência do aprendizado verificando-se também um melhor entendimento dos ritmos musicais (Chou; Chu, 2017, p. 1).

A avaliação dos aplicativos remete às possibilidades de promover o engajamento dos alunos com o aprendizado prático sem a exigência de conhecimentos musicais aprofundados. A possibilidade de execução musical digital ou mesmo performance (prática com robôs) pode qualificar a atividade didática. No entanto, a prática com o sistema MusicSpeak apresenta certa relevância no sentido de motivar a ação dos alunos com o exercício sistemático do canto. Tal atividade pode promover uma maior interação entre os alunos e um envolvimento corporal mais acentuado. Apesar do número limitado de estudos, verifica-se que o envolvimento do corpo com as práticas com aplicativos de smartphone ou tablet podem fornecer uma experiência mais completa para o aprendizado musical. Por fim, a utilização da percussão corporal e seu potencial para o trabalho rítmico através de habilidades motoras pode promover articulações úteis para a efetivação de práticas com smartphones ou tablets.

\section{Metodologia}

A metodologia tem natureza exploratória utilizando recursos de observação participante, entrevistas e questionário. O presente trabalho busca entendimentos acerca do fenômeno da percussão corporal relacionando seu uso em sala de aula para o aprendizado rítmico. A pesquisa assume a posição de que o aprendizado da notação tradicional é parte essencial do aprendizado do ritmo, mas não exclusivamente no que tange à representação musical. O uso de notações não convencionais fornece os seguintes recursos: (1) enriquecer o vocabulário representacional dos alunos demandando habilidades de percepção, avaliação e análise; (2) motivam o exercício de elaboração criativas promovendo uma produção de sentido forjada na individualidade e na coletividade; e (3) auxiliam na proximidade com as novas tecnologias.

As perguntas norteadoras da pesquisa são: o que acontece quando se utiliza a associação entre a percussão corporal e um aplicativo para tablet no aprendizado de leitura musical? Como os alunos reagem aos processos instaurados por essa prática? Como se dá a associação entre a notação digital e a notação tradicional no âmbito do aprendizado rítmico?

A coleta de dados foi realizada entre 17 de outubro e 13 de novembro de 2018. Duas unidades de uma escola técnica no Rio de Janeiro foram escolhidas para a realização da pesquisa. Uma unidade dessa instituição fica no Maracanã, região da Zona Norte da cidade. A outra fica no município de Valença, norte do Estado. Na unidade Maracanã, as aulas de música estão 
inseridas em um contexto de oficinas de artes. Assim, os alunos escolhem anualmente um tipo de oficina entre as opções de teatro, música, dança e artes plásticas. Na unidade Valença, a disciplina Artes é lecionada por um professor de música e faz parte da grade curricular dos cursos técnicos de química e engenharia de alimentos. A turma da unidade do Maracanã corresponde ao primeiro ano do ensino médio em educação tecnológica, com 20 alunos. A unidade de Valença contribuiu com duas turmas do ensino médio em educação tecnológica: o segundo ano de química apresentando 26 alunos e o primeiro ano de engenharia de alimentos apresentando 33 alunos. Os alunos têm uma faixa etária entre 13 e 15 anos. Seguem os dados demográficos dos alunos.

Tabela 1: Dados demográficos referentes aos alunos envolvidos na pesquisa.

\begin{tabular}{cccc}
\hline Caracteristicas & $\begin{array}{c}\text { Química } \\
\text { (segundo ano) }\end{array}$ & $\begin{array}{c}\text { Alimentos } \\
\text { (primeiro ano) }\end{array}$ & $\begin{array}{c}\text { Maracanã } \\
\text { (primeiro ano) }\end{array}$ \\
\hline Total de alunos & 26 & 33 & 20 \\
Mulheres & 16 & 24 & 5 \\
Homens & 10 & 9 & 15 \\
Idade (16-18) & 17 & 14 & 9 \\
Idade (14-15) & 9 & 19 & 11 \\
Cor branca & 24 & 25 & 16 \\
Cor negra & 2 & 8 & 4 \\
Alunos com & 2 & 5 & 0 \\
Bolsa Família & & & \\
\hline
\end{tabular}

\section{OBSERVAÇÃO PARTICIPANTE, ENTREVISTAS E QUESTIONÁRIO}

As observações seguiram o modelo de observação participante, que consiste na percepção dos fatos em primeira mão e o uso do próprio conhecimento e experiência em atividades interpretativas essenciais para a pesquisa (Merriam, 2009, p. 119). O uso de entrevistas semiestruturadas seguiu uma lista de perguntas, porém, ofereceu a oportunidade de alterações nas palavras ou na ordem das questões em função de ideias que surgiram das relações estabelecidas com os entrevistados (Merriam, 2009, p. 114). Os entrevistados foram escolhidos buscando diversidade concernente a dois aspectos: desenvoltura quanto à percussão corporal e adaptação ao processo de leitura com o aplicativo Medly. Foram entrevistados quatro alunos por turma totalizando 12 alunos. Os alunos foram entrevistados em duplas. Seguem as informações sobre as entrevistas. 


\begin{tabular}{|c|}
\hline A01FQ e A02MQ (17/10/2018) \\
Duração: 17 minutos e 7 segundos \\
\hline A01FEA e A02FEA (17/10/2018) \\
Duração: 12 minutos e 5 segundos \\
\hline A03MEA e A04FEA (24/10/2018) \\
Duração: 17 minutos e 17 segundos \\
\hline A03FQ e A04FQ (31/10/2018) \\
Duração: 27 minutos e 57 segundos \\
\hline A01FM e A02MM (06/11/2018) \\
Duração: 18 minutos e 47 segundos \\
\hline A03FM e A04FM (06/11/2018) \\
Duração: 18 minutos e 29 segundos \\
\hline
\end{tabular}

Quadro 1: Informações sobre os alunos entrevistados.

O questionário foi estruturado com base na busca por entendimentos acerca do fenômeno da percussão corporal em situações de aprendizado com o tablet. A estruturação de questionários deve ser norteada pela identificação de valores, percepções e interesses dos respondentes (Gray, 2012, p. 276). Quatro perguntas foram criadas para verificar as práticas de percussão corporal através de entendimentos provenientes dos resultados. Os questionários foram realizados nos dias 7 de novembro (turma de química e turma de engenharia de alimentos) e 13 de novembro (turma do Maracanã).

O presente trabalho foi aprovado pelo comitê de ética da Universidade Federal do Estado do Rio de Janeiro (UNIRIO) sob o parecer de número 2.920.926. O Registro na Plataforma Brasil apresenta o CAAE de número 95478918.8.0000.5285. A pesquisa seguiu os principios, normas e diretrizes éticas para pesquisas envolvendo seres humanos de acordo com a Resolução n. 466, de 12 de dezembro de 2012, do Conselho Nacional de Saúde (Brasil, 2012). Todos os participantes das entrevistas assinaram o Termo de Consentimento Livre e Esclarecido. Todos os participantes que realizaram questionários preencheram termos de assentimento. $\mathrm{O}$ anonimato foi preservado com a substituição do nome dos alunos por códigos. O código foi constituído pela letra "A" de aluno, o número correspondente (foram entrevistados quatro alunos por turma), o sexo (F para feminino e M para masculino) e as letras do curso técnico (Q para química, EA para engenharia de alimentos e M para Maracanã).

\section{ANÁLISE DE DADOS}

Os dados das entrevistas e dos questionários foram avaliados seguindo principios quantitativos e qualitativos. A análise seguiu o padrão de convergência entre métodos paralelos utilizando comparações e relações entre os dados (Creswell; Creswell, 2014, p. 273). O produto dessa análise se estabelece em uma discussão onde os dados são colocados lado a lado manifestando convergências e divergências. 


\section{A PRÁTICA DE PERCUSSÃO CORPORAL COM O APLICATIVO MEDLY}

O método do ritmo aplicado pelo presente estudo consiste na divisão do tempo em quatro partes, semelhante à associação das semicolcheias. ${ }^{3} \mathrm{~A}$ divisão corresponde às vogais A-U-I-U, que permitem a organização e localização na perspectiva do ritmo musical. A consoante $\mathrm{T}$ é usada para indicar o momento de bater palmas ou emitir outros sons. Dependendo da localização do T, são formadas estruturas como TA-U-I-U, A-TU-I-U, TA-U-TI-U, A-U-TI-TU, etc. Tais estruturas de sílabas apresentam símbolos correspondentes que facilitam a leitura rítmica. Na figura a seguir é possivel ver os símbolos que correspondem às estruturas das silabas, bem como a localização das palmas.

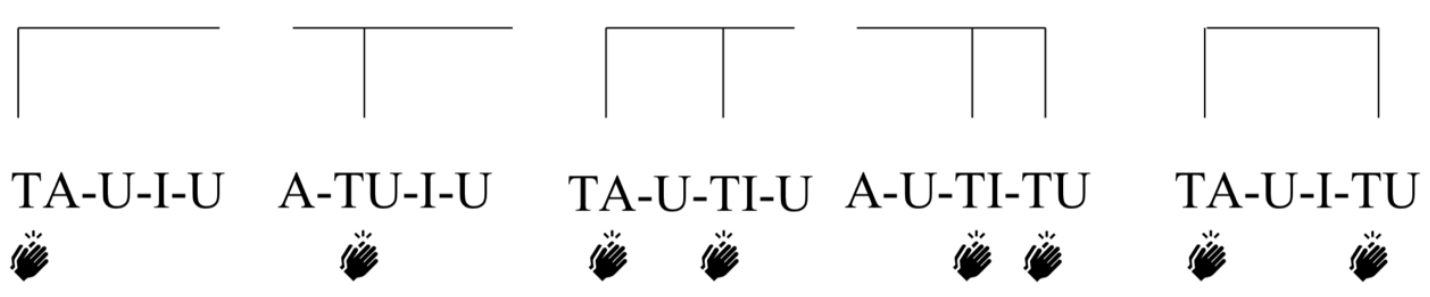

Figura 1: Os símbolos e as estruturas silábicas do método.

O professor apresentou esses símbolos atribuindo ao processo a categorização de leitura tradicional. Algumas atividades com percussão corporal foram realizadas usando a simbologia apresentada com alguns exemplos realizados com base no quadro branco. Foram utilizados três tipos de palmas para as atividades: a palma concha, a palma estrela e a palma centro, que são apresentadas na figura abaixo.

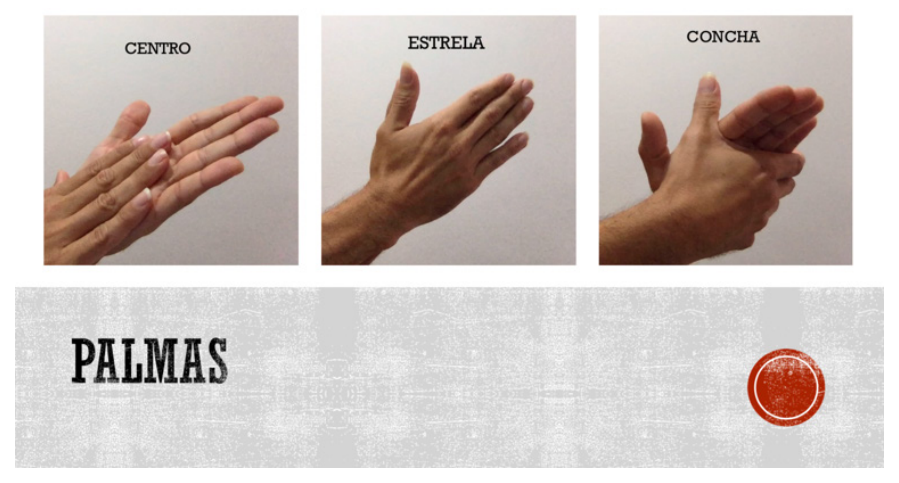

Figura 2: As palmas utilizadas.

\footnotetext{
3 Essa divisão foi desenvolvida segundo uma associação entre o método Gazzi de Sá e o de Ciavatta (1996).
} 
O aplicativo Medly permite a criação musical através do uso de timbres digitais que imitam instrumentos (sintetizadores, arpejos, baixos, pianos e bateria). Existe também a opção de gravar o próprio áudio através do microfone do dispositivo ou outra forma de captação. O Medly apresenta um mapa de notas que se assemelha a um tabuleiro indicando uma tendência de inserir a notação tradicional em um contexto lúdico. É possivel ajustar o andamento em BPMs e escolher as tonalidades no caso de instrumentos com altura definida. Em situações onde os usuários não apresentam conhecimentos musicais aprofundados é possivel escolher entre escala simples (pentatônica), maior e menor (Figura 3).
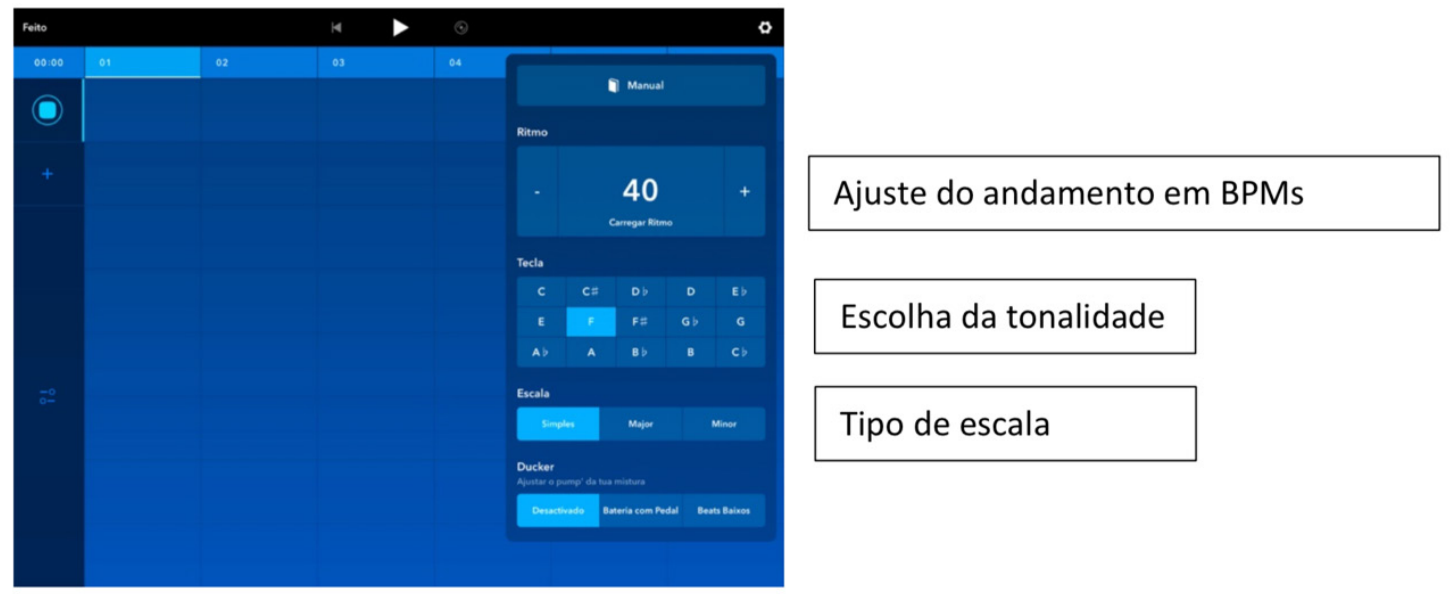

Figura 3: Escolha de andamento, tonalidade e tipo de escala.

Para registrar os sons é necessário tocar na tela de acordo com a localização que corresponda ao som e à divisão do tempo desejados. Ao dar "play" no aplicativo surge um cursor que cruza o tabuleiro mostrando as notas que estão sendo tocadas (Figura 4).

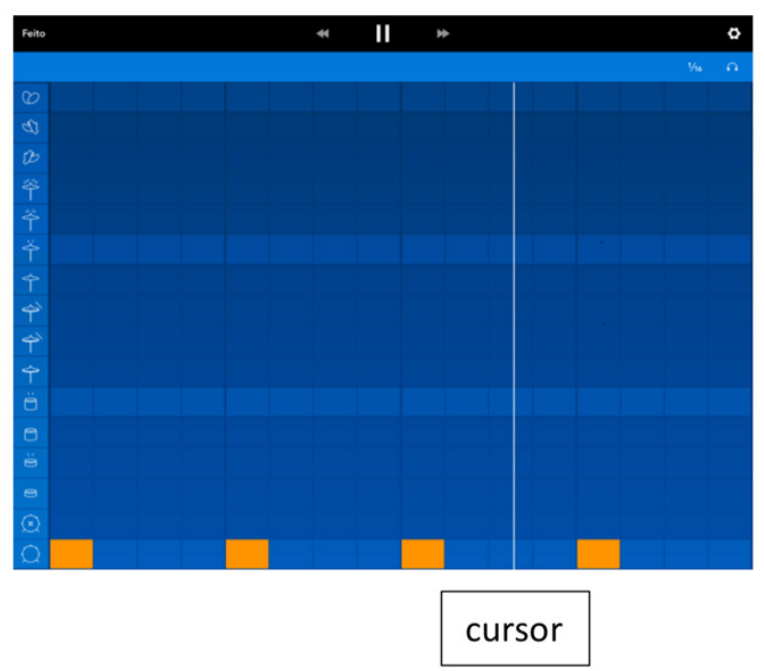

Figura 4: O cursor e a localização das notas. 
A prática aqui apresentada utilizou o tabuleiro correspondente à bateria. A figura abaixo demonstra como as sílabas são representadas por meio de quadrados na tela do aplicativo.

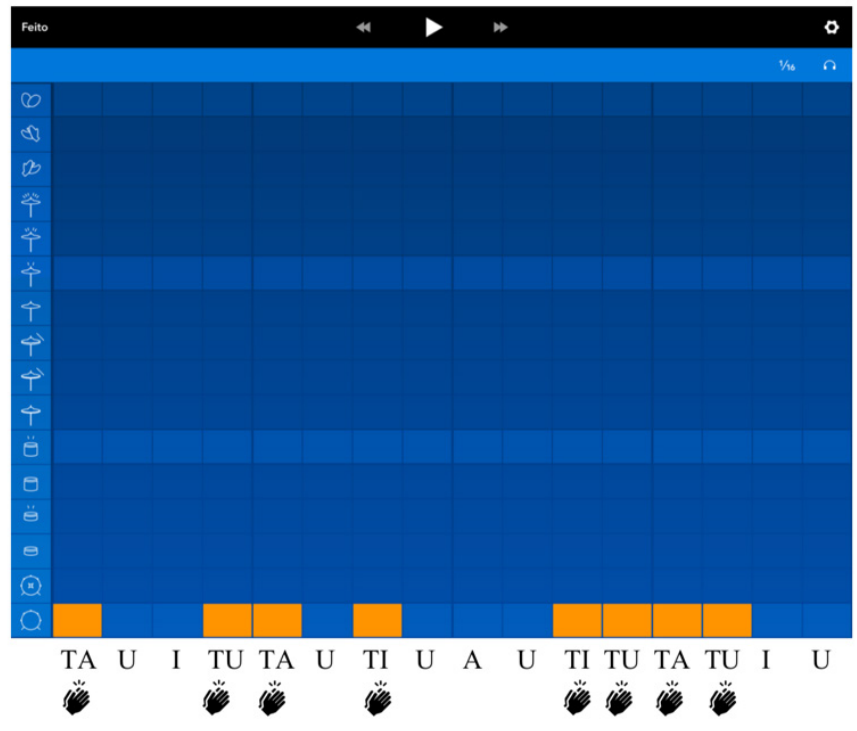

Figura 5: As sílabas do método inseridas na prática com o aplicativo Medly.

O professor pediu que os alunos observassem a interface do aplicativo projetada sobre o quadro através de um Datashow. As palmas estrela, centro e concha foram associadas aos sons de bateria presentes no tabuleiro. Assim, os alunos deveriam seguir os simbolos de cada parte. Esse processo foi categorizado como leitura digital.

\section{RESULTADOS}

O questionário ofereceu quatro questões com quatro ou três opções. Os alunos foram instruídos a marcar uma opção por questão. A tabela a seguir apresenta as questões e as porcentagens de resposta para cada opção. 
Tabela 2: Perguntas e os resultados quantitativos correspondentes.

\begin{tabular}{|c|c|c|c|}
\hline Respostas & $\begin{array}{c}\text { Turma } \\
\text { de quimica }\end{array}$ & $\begin{array}{c}\text { Turma } \\
\text { de alimentos }\end{array}$ & $\begin{array}{l}\text { Turma } \\
\text { Maracanã }\end{array}$ \\
\hline \multicolumn{4}{|l|}{$\begin{array}{l}\text { As aulas de artes motivaram } \\
\text { a busca de informações sobre } \\
\text { aplicativos de música? }\end{array}$} \\
\hline Sim, pois fiquei curioso & $19,23 \%(5)$ & $57,58 \%(19)$ & $35 \%(7)$ \\
\hline $\begin{array}{l}\text { Sim, pois estudo música } \\
\text { e o interesse foi natural }\end{array}$ & $15,38 \%(4)$ & $9,09 \%(3)$ & $10 \%(2)$ \\
\hline $\begin{array}{l}\text { Não, mas me interessei } \\
\text { pelos aplicativos }\end{array}$ & $50,00 \%(13)$ & $27,27 \%(9)$ & $40 \%(8)$ \\
\hline $\begin{array}{l}\text { Não, pois não me interesso } \\
\text { por tais aplicativos }\end{array}$ & $15,38 \%(4)$ & $6,06 \%(2)$ & $15 \%(3)$ \\
\hline \multicolumn{4}{|l|}{$\begin{array}{l}\text { Nas práticas que relacionaram } \\
\text { a música dos aplicativos com } \\
\text { o corpo... }\end{array}$} \\
\hline $\begin{array}{l}\text { Senti dificuldade, pois não } \\
\text { ouvi direito o som }\end{array}$ & $11,54 \%(3)$ & $3,03 \%(1)$ & $0 \%(0)$ \\
\hline $\begin{array}{l}\text { Senti dificuldade, pois precisei } \\
\text { ficar muito concentrado }\end{array}$ & $34,62 \%(9)$ & $18,18 \%(6)$ & $15 \%(3)$ \\
\hline $\begin{array}{l}\text { Não tive nem facilidade nem } \\
\text { dificuldade }\end{array}$ & $38,46 \%(10)$ & $45,45 \%(15)$ & $75 \%(15)$ \\
\hline Tive facilidade com a prática & $15,38 \%(4)$ & $30,30 \%(10)$ & $5 \%(1)$ \\
\hline \multicolumn{4}{|l|}{$\begin{array}{l}\text { Qual das leituras ensinadas } \\
\text { em sala é mais fácil? }\end{array}$} \\
\hline Leitura tradicional & $46,15 \%(12)$ & $39,39 \%(13)$ & $20 \%(4)$ \\
\hline Leitura digital & $3,85 \%(1)$ & $9,09 \%(3)$ & $15 \%(3)$ \\
\hline Leitura digital com som & $50,00 \%(13)$ & $51,52 \%(17)$ & $65 \%(13)$ \\
\hline \multicolumn{4}{|l|}{$\begin{array}{l}\text { Na prática de leitura em grupo } \\
\text { você presta mais atenção... }\end{array}$} \\
\hline $\begin{array}{l}\text { Para os simbolos digitais } \\
\text { na tela? }\end{array}$ & $61,54 \%(16)$ & $18,18 \%(6)$ & $60 \%(12)$ \\
\hline Para a percussão corporal? & $26,92 \%(7)$ & $27,27 \%(9)$ & $20 \%(4)$ \\
\hline Para o som do aplicativo? & $0 \%(0)$ & $39,39 \%(13)$ & $10 \%(2)$ \\
\hline Para o som da turma? & $11,54 \%(3)$ & $15,15 \%(5)$ & $10 \%(2)$ \\
\hline
\end{tabular}




\section{PRIMEIRA PERGUNTA: "AS AULAS DE ARTES MOTIVARAM A BUSCA DE INFORMAÇÕES SOBRE APLICATIVOS DE MÚSICA?”}

O exame das respostas da primeira pergunta demonstra que os quantitativos referentes ao desinteresse das turmas quanto à busca de informações acerca dos aplicativos foi baixo - 15,38\% (4) na turma de química, 6,06\% (2) na turma de engenharia de alimentos e $15 \%$ (3) na turma do Maracanã. Observando o grupo de alunos que não procuraram informações, os quantitativos de alunos que se interessaram pelos aplicativos foi razoável - 50,00\% (13) na turma de química, $27,27 \%$ (9) na turma de engenharia de alimentos e $40 \%$ (8) na turma do Maracanã. As entrevistas mostraram que alguns alunos não apresentaram interesse pelos aplicativos e foram bastante diretos quanto a isso.

(A04FM, 06/11/2018): Não, sinceramente eu nunca tive interesse por nada de música, assim.

(A01FEA, 17/10/2018): Ah, a gente acaba baixando os que você pede e em casa a gente acaba mexendo neles.

Alguns alunos já apresentavam alguma ligação com a prática musical. Tal inclinação pode ter facilitado o aumento do interesse pelos aplicativos.

(A03MEA, 24/10/2018): Na verdade eu estava procurando uns aplicativos pra fazer umas músicas, umas batidas assim, ai depois que você mostrou os aplicativos certos eu comecei a procurar mais.

(A04FEA, 24/10/2018): Só depois que você ensinou alguns modos de usar que eu comecei a tentar ir direito, que eu tava tentando criar ritmo pra mim mesma, fazer essas coisas assim.

(A01FM, 06/11/2018): Eu comecei a usar o aplicativo de música voltado pro violão, porque eu comecei a apren... a tocar violão sozinha. E eu comecei a procurar uns aplicativos, mas nunca tive esse interesse tão grande de pesquisar mus... eh, aplicativos pra remix. Nunca me despertou esse interesse, mas quando eu vi na aula, aí eu... [me interessei].

Os alunos relataram algumas potencialidades dos aplicativos devido à experiência acumulada.

(A02MM, 06/11/2018): Eu nunca tive contato, assim, a primeira vez foi quando você mostrou. E eu achei interessante porque, tipo, dá pra você se divertir, dá pra você aprender, então fica uma coisa legal, não fica cansativa, tipo, você vai pra aula de violão e tem que aprender cada acorde...

(A01FQ, 17/10/2018): Eu acho legal a gente começar a criar uma nova melodia pras músicas, eu acho que isso foi muito legal. 


\section{SEGUNDA PERGUNTA: "NAS PRÁTICAS QUE RELACIONARAM A MÚSICA DOS APLICATIVOS COM O CORPO..."}

A opção que apresentou o quantitativo de escolhas mais expressivo na segunda pergunta foi o de alunos que alegaram não terem apresentado nem facilidade nem dificuldade com a prática - 38,46\% (10) na turma de química, $45,45 \%$ (15) na turma de alimentos e 75\% (15) na turma do Maracanã. O quantitativo de respostas provenientes de alunos da turma do Maracanã foi consideravelmente maior do que o das outras turmas. O baixo número de alunos da turma pode ter contribuído para o resultado, pois com menos alunos a prática se torna mais confortável.

Cerca de 30,30\% (10) da turma de engenharia de alimentos declararam que tiveram facilidade na execução da prática. Esse quantitativo foi expressivo em relação as outras turmas - 15,38\% (4) na turma de química e 5\% (1) na turma do Maracanã. Além disso 45,45\% (15) alegaram não apresentar nem facilidade nem dificuldade. A leitura desses dados remete que a turma de engenharia de alimentos pode ter se adaptado melhor a esse tipo de atividade. As turmas de química e do Maracanã apresentaram um resultado diferente da turma de engenharia de alimentos. Na turma de química, 34,62\% (9) alegaram que sentiram dificuldade, pois tiveram que se concentrar muito, em contraste com 15,38\% (4) que alegaram não apresentar nem facilidade nem dificuldade. Na turma do Maracanã, 15\% (3) alegaram que sentiram dificuldade, pois tiveram que se concentrar muito, em contraste com 5\% (1) que alegaram não apresentar nem facilidade nem dificuldade.

No relato dos alunos é possivel identificar que o processo pode motivar os alunos.

(A02MQ, 17/10/2018): Eu acho que deu sim, de um jeito mais descontraído pra gente entender, porque a gente às vezes... é um instrumento... mas a gente conseguia representar aquele instrumento numa coisa que era totalmente diferente (movimentos do corpo), a gente conseguia entender melhor o ritmo, se era mais acelerado.

(A01FQ, 17/10/2018): E nem todo mundo se sente à vontade, mas como você descontraiu, todo mundo entrou.

No entanto, os alunos podem sentir dificuldades devido à necessidade de dar respostas em tempo real.

(A02MM, 06/11/2018): Eu senti um pouco de dificuldade, porque, tipo, se eu for gravar uma coisa eu demoro um pouco, mas depois eu gravo mermo. Então, tipo, se você for passar alguma coisa muito rápida, tipo, a primeira prova que tu passou que era, que era tipo um testezinho que tu passava ta, ta-tum-ti. Eu demoro um pouco pra pegar. 
(A04FEA, 24/10/2018): Aprender a controlar o tempo entre uma passada e outra também dava uma noção do r... como o ritmo vareia, mesmo a gente não percebendo, mas ele vareia quando a gente põe a tensão na música.

Houve casos de dificuldade acentuada.

(A03FQ, 31/10/2018): Hum hum... porque, que nem ela falou, é muito mais dificil, tipo, coordenar o que eu tô fazendo, tipo, com o que eu tô ouvindo do que com o que eu tô lendo, porque aí o meu som tá atrapalhando o som dele e o som dele tá me atrapalhando.

(A04FM, 06/11/2018): Eu acho que tem que ser muito focado, porque eu pelo menos, particularmente, fico vendo o antes, entendeu? O depois, entendeu [se corrigindo]? Eu não foco no agora. Eu fico vendo o que vai acontecer depois acontecendo depois, aí que me embolo no agora, no depois e não consigo fazer nada.

Algumas aulas foram realizadas no auditório, o que pode ter impactado o processo.

(A03FQ, 31/10/2018): Ah, o ruim é aquele monte de gente que tá ali na sua frente...

(A04FQ, 31/10/2018): É o auditório, eu acho que o auditório não é um lugar bem apropriado porque tem espaço e não tem espaço.

\section{TERCEIRA PERGUNTA: “QUAL DAS LEITURAS ENSINADAS EM SALA É MAIS FÁCIL?”}

A leitura digital com som foi identificada como a mais fácil - 50,00\% (13) na turma de quimica, $51,52 \%$ (17) na turma de engenharia alimentos e $65 \%$ (13) na turma do Maracanã. A leitura tradicional foi a segunda opção mais escolhida - 46,15\% (12) na turma de química, $46,15 \%$ (12) na turma de engenharia de alimentos e $20 \%$ (4) na turma do Maracanã. A diferença entre os quantitativos dessas duas opções foi menor na turma de química - 3,85\% (1). Nas turmas de engenharia de alimentos e do Maracanã a diferença foi expressiva $-12,13 \%$ (5) e $45 \%$ (9). Os alunos relataram algumas conveniências do uso do aplicativo com som.

(A01FEA, 17/10/2018): Acho que serviu pra entender o ritmo, fica melhor.

(A02FEA, 17/10/2018): Acho que ouvir o aplicativo, quanto tempo demora. 
(A01FEA, 17/10/2018): Ajuda, porque fica todo mundo meio que acompanhando.

(A02FEA, 17/10/2018): Sabendo onde tá.

(A04FEA, 24/10/2018) [Enfática]: Eu acho que o aplicativo facilitou a gente ter uma observação na hora que a gente fosse fazer a percussão com o corpo.

Uma aluna apresentou uma defesa da leitura tradicional.

(A01FM, 06/11/2018): Porque a tradicional a gente tá sempre acostumado com uma, uma linguagem tradicional também de escrita. E eu acho que a digital ela tá vindo, assim, tem, com a evolução da tecnologia tá, tá se evoluindo isso e acho que isso é muito bom por, por causa do aprimoramento, mas eu sou mais acostumada com a linguagem tradicional.

A articulação entre a leitura tradicional e a leitura digital pode trazer efeitos benéficos na opinião dos alunos.

(A02MQ, 17/10/2018): Eu acho que as duas juntas, elas melhoram, você passou no quadro e viu a parte da teoria, aí a gente viu na prática eu acho que isso ajuda a penetrar na cabeça melhor.

(A02FEA, 17/10/2018): Eu acho que, tipo, de aprender é melhor a do quadro [notação tradicional], mas quando você já sabe é mais fácil a digital, sabe?

\section{QUARTA PERGUNTA: "NA PRÁTICA DE LEITURA EM GRUPO VOCÊ PRESTA MAIS ATENÇÃO..."}

O quantitativo de alunos na turma de química e do Maracanã que alegaram ter mais atenção nos símbolos na tela é alto - 61,54\% (16) na turma de engenharia de alimento e $60 \%$ (12) na turma do Maracanã. A turma de engenharia de alimentos apresenta o mais alto quantitativo de alunos que prestam atenção no som do aplicativo - 39,39\% (13). As turmas de química e do Maracanã se caracterizam por ter muita concentração nas aulas expositivas, fato que foi destacado vários alunos. Assim, é possivel que a concentração apresentada pelas turmas motive os alunos a focar com maior intensidade em elementos visuais em detrimento da referência sonora. Os relatos demonstram um alto número de atribuições aos aspectos visuais.

(A04FEA, 24/10/2018): Eu acabei associando cada ritmo a tipo um quadrado, cada vez que batia era como se um quadrado piscasse assim, junto, aí quanto mais perto, por exemplo, o TA 
era um quadrado grande, aí vinha o TA-TI, aí já vinha dois quadrados, já juntos assim, proporcionais.

(A02MM, 06/11/2018): Ele [o cursor] ajuda porque, ele ajuda a, tipo, dá uma sincronia pra turma toda, ajuda as pessoas se acharem no meio da música.

(A01FM, 06/11/2018): Sim, e também e, é, a criação dessa linha que vai passando, ela é muito importante porque, e também facilita muito porque você tem uma visão geral do ritmo inteiro e você vai acompanhando e isso é muito bom. Facilita muito.

Os alunos alegam que se guiar pelo som da turma pode ser prejudicial.

(A03FM, 06/11/2018): O aplicativo, porque às vezes a turma tá completamente fora do ritmo, mas se a gente se concentra no ritmo do aplicativo a gente consegue fazer direitinho.

(A03FQ, 31/10/2018): Ainda mais que a gente é um monte de gente...

(A04FQ, 31/10/2018): Que tá tentando entrar em sintonia, e tipo, igual a última aula, tinha gente que tava, tipo, mais rápido, aí eu tava percebendo isso, eu tava, tipo, eu vou mais rápido ou eu vou no meu ritmo mesmo ou o que eu faço?

\section{DISCUSSÃO E CONCLUSÃO}

As aulas de música podem ter elevado o interesse dos alunos pela busca de informações acerca dos aplicativos de música. A ligação com a música e o engajamento com o aprendizado de instrumentos pode ter propiciado condições favoráveis para esse processo como evidenciado nas entrevistas. A correlação entre o caráter lúdico da turma de alimentos e o quantitativo alto de alunos que alegaram a busca por informações dos aplicativos leva a crer que podem existir diferentes formas de interesse em consequência das características de uma turma. Vale destacar também a necessidade de buscar mais entendimentos acerca dos alunos que mesmo interessados não efetivaram buscas sobre os aplicativos.

Esses achados se inserem em um panorama mais amplo no qual os alunos são expostos a uma quantidade considerável de informações, experimentando aprendizados de diversas origens. A existência desses novos saberes demanda um posicionamento dos educadores, evidenciando situações potencialmente delicadas. Apesar de saudável a inclusão de conhecimentos dos alunos acerca de música e aplicativos de smartphone nas atividades escolares, muitos conhecimentos podem apresentar inconsistências. Tomar decisões acerca da inclusão dos conhecimentos dos alunos termina por demandar habilidades interpessoais no sentido de incentivar, aconselhar e desaconselhar 
sem desmotivar o aluno. Conseguir equilibrar essas ações apresenta grande dificuldade, exigindo experiência e abertura por parte dos docentes.

Os processos instaurados pela prática de percussão corporal com aplicativos provocou motivação por parte dos alunos. Tal elemento se associa com outros estudos da área de smartphones e tablets (Chou; Chu, 2017; Palazón Herrera, 2014). Apesar de um grande contingente de alunos responder que não sentiu nem facilidade nem dificuldade com a prática, alguns problemas ficaram evidentes. Apesar de a turma de engenharia de alimentos ter alegado um bom desempenho, a turma de quimica alegou que as práticas demandaram alta concentração. Outro dado relevante foi o de que com exceção da turma de engenharia de alimentos os quantitativos referentes à opção "não tive dificuldade com a prática" foram baixos. As entrevistas apresentaram temas que impactaram no desenvolvimento do processo, como a dificuldade de reagir às mudanças de padrões rítmicos e à variação do andamento.

O aplicativo Medly apresenta algumas conveniências para as práticas de ritmo em sala de aula. A presença do cursor faz com que a turma compartilhe da mesma referência favorecendo a sincronia em grupos grandes. Além disso, o registro sonoro faz com que alunos com dificuldade possam compartilhar da atividade em grupo fazendo com que se sintam incluídos no processo. Esses aspectos também geraram beneficios em outros estudos acerca de tecnologias digitais (Chou; Chu, 2017; Wang; Mok; Meng, 2016). Vale a pena verificar que as atividades de leitura rítmica em grupo são valiosas para a coesão da turma na participação de todos em um processo de aprendizado comum e compartilhado. Além disso, seu design e sua animação fazem referência ao contexto dos games, criando um apelo específico para os jovens.

As novas formas de notação musical em meios digitais apontam para questões que demandam reflexões. Os elementos gráficos podem ofertar apoio para as práticas musicais como o uso de um cursor e associação entre elementos visuais e auditivos. No entanto, verifica-se que a inclusão da notação digital faz emergir novos problemas como a falta de adaptação de determinados alunos, a adequação do ambiente da sala da aula e a relação do som da turma com o som dos aplicativos. Novas práticas criam novas experiências exigindo a criação de uma nova expertise por parte dos professores. Tal fenômeno efetiva reflexões acerca do papel do professor em sala de aula, habilidades técnicas e conhecimentos mais aprofundados quanto às habilidades dos alunos. Por outro lado, o apoio que os recursos ofertam pode gerar facilidades de forma exagerada tirando o desafio das práticas. Cabe ao professor entender quando tais atividades podem ser inseridas criando parâmetros para dosar ou mesmo trocar de prática para melhorar o processo de aprendizado. Se faz necessário avaliar as demandas de cada turma e a adequação dessas práticas aos objetivos estabelecidos pela disciplina (Duarte; Marins, 2015).

A criação de estudos associando técnicas de percussão corporal com o aprendizado de conceitos tradicionais pode trazer achados oportunos para o campo da educação musical. Os futuros estudos desse campo podem abranger a investigação de timbres ou mesmo conceitos de altura definida. O uso de aplicativos de smartphone para esse fim se fez relevante para o desenvolvimento 
das atividades. Novos estudos podem ser realizados com o objetivo de ampliar os entendimentos acerca dos estilos de aprendizado dos alunos, da adequação das práticas ao ambiente escolar e as habilidades interpessoais envolvidas. $\mathrm{O}$ presente estudo apresenta limitações por se basear em dados autorrelatados através de opiniões dos alunos, exigindo novos estudos para dar robustez aos entendimentos produzidos.

\section{REFERENNCIAS}

AMORIM, Roberto Ricardo Santos de. Batucadeiros: educação musical por meio da percussão corporal. 2016. Dissertação (Mestrado em Música) Universidade de Brasília, Brasília, 2016.

AZARYAHU, Libby; COUREY, Susan Joan; ELKOSHI, Rivka; ADI-JAPHA, Esther. 'MusiMath' and 'Academic Music' - two music-based intervention programs for fractions learning in fourth grade students. Developmental Science, [s. l.], v. 23, n. 4, e12882, July 2019.

BANO, Muneera; ZOWGHI, Didar; KEARNEY, Matthew; SCHUCK, Sandra; AUBUSSON, Peter. Mobile learning for science and mathematics school education: a systematic review of empirical evidence. Computers and Education, [s. l.], v. 121, p. 30-58, June 2018.

BARBA, Fernando; NÚCLEO EDUCACIONAL BARBATUQUES. O corpo do som: experiências do Barbatuques. Música na Educação Básica, Brasília, v. 5, n. 5, p. 39-49, 2013.

BRASIL. Ministério da Saúde. Conselho Nacional de Saúde. Resolução $n^{\circ}$ 466, de 12 de dezembro de 2012. Brasília: CNS, 2012. Disponivel em: https://bvsms.saude.gov.br/bvs/saudelegis/cns/2013/ res0466_12_12_2012.html. Acesso em: 10 dez. 2019.

BRODSKY, Warren; SULKIN, Idit. Handclapping songs: a spontaneous platform for child development among 5-10-year-old children. Early Child Development and Care, [s. l.], v. 181, n. 8, p. 1111-1136, 2011.

CHOU, Chien-Hsing; CHU, Yung-Long. Interactive rhythm learning system by combining tablet computers and robots. Applied Sciences, Basel, v. 7, n. 3, art. 258, 2017.

CIAVATTA, Lucas. O passo. Rio de Janeiro: Instituto d'O Passo, 1996.

CREMADES ANDREU, R. El desarrollo del ritmo a través de la percusión corporal, el lenguaje y la improvisación en la educación primaria. In: RAMOS, Fernando Sadio (coord.). Diálogo e comunicação intercultural: a educação com as artes. Sevilla: Junta de Andalucia, 2009. p. 159-178. 
CRESPO-COLOMINO, Natalia; ROMERO-NARANJO, Francisco Javier. Body percussion and dyslexia. theoretical and practical contribution through the BAPNE method. Procedia: Social and Behavioral Sciences, [s. 1.], v. 132, p. 686-690, 2014.

CRESWELL, John W.; CRESWELL, J. David. Research design: qualitative, quantitative, and mixed method. London: Sage, 2014.

CROMPTON, Helen; BURKE, Diane. The use of mobile learning in higher education: a systematic review. Computers and Education, [s. l.], v. 123, p. 53-64, Apr. 2018.

CUERVO, Luciane da Costa. Educação musical e novas tecnologias digitais: recursos e estratégias no contexto do canto e da flauta doce. Orfeu, Florianópolis, v. 4, n. 1, p. 120-150, 2019.

DORAIRAJU, Regina; JAMBULINGAM, Manimekalai. The role of music and m-learning in English: vocabulary gain among tertiary students. Journal of Language and Education, Moscow, v. 3, n. 2, p. 39-44, 2017.

DUARTE, Alex; MARINS, Paulo Roberto Affonso. Um estudo sobre a utilização de aplicativos para tablets e smartphones no ensino da música. In: CONGRESSO NACIONAL DA ASSOCIAÇÃO BRASILEIRA DE EDUCAÇÃO MUSICAL, 22., Natal, 2015. Anais [...] Natal: Abem, 2015. p. 1-13.

FABRA-BRELL, Eugenio; ROMERO-NARANJO, Francisco Javier. Body percussion: social competence between equals using the method BAPNE in secondary education (design research). Procedia: Social and Behavioral Sciences, [s. 1.], v. 237, p. 1138-1142, 2017 a.

Social competence between equals through body percussion according to method BAPNE in secondary students. Procedia: Social and Behavioral Sciences, [s. l.], v. 237, p. 829-836, 2017b.

GRAY, David E. Pesquisa no mundo real. Porto Alegre: Penso, 2012.

KARTOMI, Margaret. The art of body percussion and movement in Aceh and its links in countries around the northern rim of the Indian Ocean and the Mediterranean. In: CONFERENCE ON MUSIC IN THE WORLD OF ISLAM, $1 .$, 2007, Assilah. Proceedings [...], Assilah: CFPCI, 2007. p. 1-12.

MERRIAM, Sharan B. Qualitative research: a guide to design and implementation. San Francisco: Jossey-Bass, 2009.

MESQUITA, Cláudia Maria. Percussão corporal no ensino de música: três atividades para a educação básica. Música na Educação Básica, Londrina, v. 7, n. 7/8, p. 47-59, 2016. 
MUNARI, Elisa de; COZZUTTI, Giorgio; ROMERO-NARANJO, Francisco Javier. Music and movement: a comparative study between the BAPNE and Suzuki Methods. SHS Web of Conferences, Les Ulis, v. 26, art. 01099, 2016.

NEDEL, Mariana Zamberlan. Aprendendo a partir da experiência em grupo: ritmos e expressão corporal para a educação infantil. Revista da SPAGESP, Ribeirão Preto, v. 11, n. 2, p. 64-77, 2010.

PALAZÓN HERRERA, José. Aprendizaje móvil basado en microcontenidos como apoyo a la interpretación instrumental en el aula de música en secundaria. Pixel-Bit: Revista de Medios y Educación, Sevilla, n. 46, p. 119136, 2014.

PEREIRA, Nayana Torres. A percussão corporal no coral e em sala de aula. In: SIMPÓSIO BRASILEIRO DE PÓS-GRADUAÇÃO EM MÚSICA, 5., 2018, Rio de Janeiro. Anais [...]. Rio de Janeiro: UNIRIO, 2018. p. 220-231.

ROMERO-NARANJO, Francisco Javier. Science \& art of body percussion: a review. Journal of Human Sport and Exercise, Alicante, v. 8, n. 2, p. 442-457, 2013.

Body percussion and memory for elderly people through the BAPNE method. Procedia: Social and Behavioral Sciences, [s. 1.], v. 132, p. 533-537, 2014.

ROMERO-NARANJO, Francisco Javier; CRESPO-COLOMINO, Natalia; LIENDO-CÁRDENAS, Adreina; PONS-TERRÉS, Jessica Maria; CARRETEROMARTÍNEZ, Andrea. Drugs and body percussion: rehabilitation therapy using the BAPNE method. Procedia: Social and Behavioral Sciences, [s. 1.], v. 152, p. 1128-1132, 2014.

WANG, Hao; MOK, Peggy; MENG, Helen. Capitalizing on musical rhythm for prosodic training in computer-aided language learning. Computer Speech and Language, [s. l.], v. 37, p. 67-81, 2016.

ZHOU, Yinsheng; PERCIVAL, Graham; WANG, Xinxi; WANG, Ye; ZHAO, Shengdong. MOGCLASS: a collaborative system of mobile devices for classroom music education. In: ASSOCIATION FOR COMPUTING MACHINERY MULTIMEDIA INTERNATIONAL CONFERENCE, 18., 2010, Firenze. Proceedings [...] Firenze: ACM, 2010. p. 671-674. 
Marcio Pizzi de Oliveira é mestre e o doutor pela Universidade Federal do Rio de Janeiro (UFRJ) na área de Música e Educação. Realizou o curso de Bacharelado em Música Popular Brasileira e o curso de Licenciatura em Música ambos pela Universidade Federal do Estado do Rio de Janeiro (UNIRIO). Atuou por quatro anos no departamento de Propaganda e Marketing como professor concursado da Fundação de Apoio a Escola Técnica (Faetec). É atualmente professor EBTT concursado do Centro Federal de Educação Tecnológica Celso Suckow da Fonseca (Cefet-RJ) na unidade Valença. Tem experiências nas áreas de produção musical, tecnologias digitais e recursos na área de educação musical. Tem como interesse as áreas de interdisciplinaridade, metodologias ativas e mercado musical. https://orcid.org/0000-0001-5102-8888 